\title{
THE EFFECT OF THE IRRADIATION OF DIFFERENT STAGES IN MICROSPOROGENESIS ON CHIASMA FREQUENCY
}

\author{
C. W. LAWRENCE \\ Wantoge Research Laborotories, Atomic Energy Research Establishment
}

\section{INTRODUCTION}

Received 28.x.60

INVESTIGATIONs into the effect of irradiation on chiasma frequency in a variety of organisms have led to conflicting results. In a number of cases (Mather, 1934; Darlington and La Cour, 1953) an increase in chiasma frequency after irradiation has been observed, while in others (Darlington and La Cour, 1953; Sybenga, 1960) no change or even a decrease (Marquardt, I95I) was found. It is difficult to determine the reason for the different responses in these experiments, for they may stem from a number of different factors. First there are those that are biological in origin, such as inherent differences between the species and variation in the developmental stage during which radiation was applied. Secondly, there are physical factors such as the nature of the radiation employed and the temperature during irradiation.

The following account describes an experiment which attempts to determine the effect on chiasma frequency of the irradiation of different developmental stages in microsporogenesis. It was hoped that in this way some information might be gained on the mechanisms underlying the formation of chiasmata.

\section{MATERIAL AND METHOD}

Plants of Lilium longiflorum var. "White Queen", obtained from P. de Jager \& Sons, Keiloo, Holland, were used for the experiment. It has been shown, (Erickson, 1948; Taylor and McMasters, 1954) that in this species there is a high correlation between the length of the flower bud and the development of the pollen mother cells. Thus treatment may be given at particular stages in sporogenesis, both before and during meiosis, with considerable accuracy. A further advantage of the species is the moderate number of large chromosomes $(2 n=24)$, among which the two pairs of long chromosomes, with median and submedian centromeres respectively, may easily be distinguished from the remaining ten pairs of short chromosomes which have sub-terminal centromeres.

A number of bulbs were planted in pots, placed in a glasshouse, and then randomly assigned to nine groups. The plants of one of these remained unirradiated, while the plants in the remaining eight groups received 30 rads of gamma rays given at Io rads $/ \mathrm{min}$. from a cobalt-6o source specially designed and calibrated for accurate work with low doses (Murray, 1959). The irradiation was carried out in air at $25^{\circ} \mathrm{C}$. Each plant was irradiated when the first bud was of a particular length, the eight groups being comprised of plants treated when their first buds were either I0, 12, 14, I6, 18, 20 or $22 \mathrm{~mm}$. long. The stage in sporogenesis to which each of these bud lengths corresponded was determined in a number of plants 
from the same batch grown under the same conditions, and was found to agree very closely with those given by Erickson (1948) and Taylor and McMasters (1954).

For cytological examination anthers were dissected from the buds and fixed in acetic alcohol $1: 3$. Fixation was carried out when the buds were $22.5 \mathrm{~mm}$. long, the majority of p.m.c.'s being at metaphase I at this time. Only the first bud on each stem was used in the experiment. Carmine or orcein squashes were made from one anther per bud, and the number of chiasmata was scored in a random sample of twenty cells at metaphase I. Each slide was coded and thus the particular treatment given to the plant was unknown to the scorer. In all 32 plants were scored.

\section{RESULTS}

The average chiasma frequency, expressed as chiasmata per bivalent, for each of the nine groups is given in fig. I. It can be seen

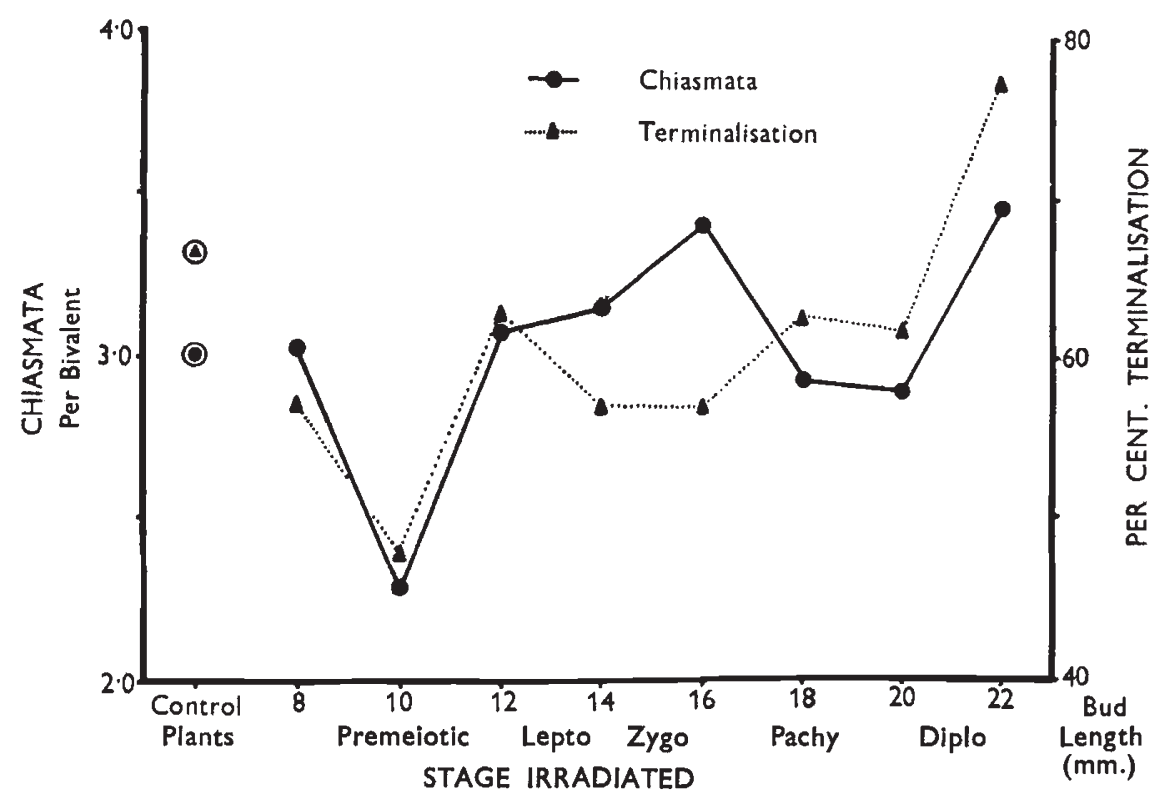

FIG. I

from the figure that while irradiation at bud lengths of 8 , I2, I4, 18 and $20 \mathrm{~mm}$. has little effect on chiasma frequency, there is a marked response at bud lengths Io, 16 and $22 \mathrm{~mm}$. The analysis of variance within and between groups given in table I shows that this variation between the treatments is significant at the I per cent. level (table I, item I (ii)). It is extremely unlikely that such responses can be attributed to variations in the environment at the time of fixation. The plants grew at greatly different rates and the four control plants for example were fixed on dates distributed evenly over the whole of the fixation period, which lasted three weeks. Thus the different groups of plants were fixed in roughly the same period. It must be concluded, therefore, that each response is the result of irradiating at these particular stages in microsporogenesis. 
The first, sensitive stage, during which irradiation produced a marked drop in chiasma frequency, occurs just before the start of meiosis (fig. I). Plants irradiated during this period not only had a much lower chiasma frequency but also were distinguished by the presence of univalent pairs and extensive chromosome uncoiling. Irradiation during the other two sensitive periods, that of late zygotene-early pachytene and of late diplotene (fig. I) produced an increase in chiasma frequency, but the metaphase chromosomes were in all other respects completely normal.

A crude but nevertheless useful indication of a change in the position of the chiasmata after the various treatments, may be obtained from the amount of terminalisation. This is most usefully expressed as the percentage of the paired chromosome arms which have terminal

TABLE I

Analysis of variance of the average chiasma frequency

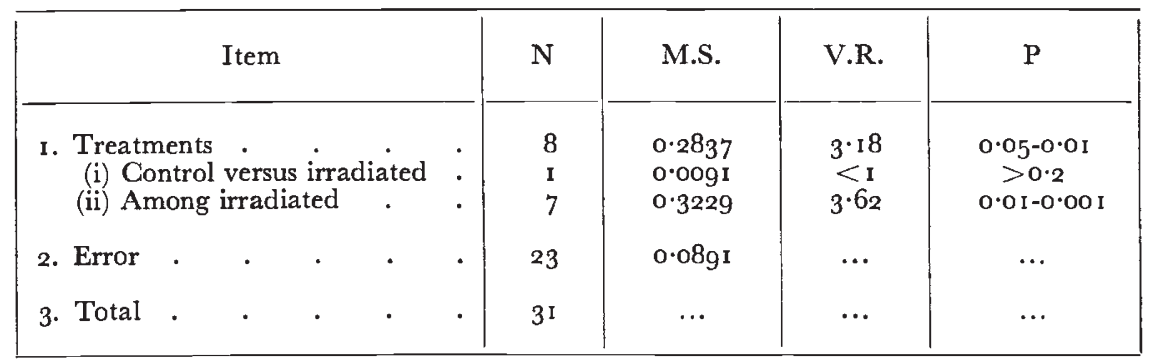

chiasmata (Rees, 1955). The average amount of terminalisation for each of the groups is given in fig. I. From the figure it can be seen that the drop in chiasma frequency after irradiation during the first sensitive period was much more marked at the ends of the chromosomes than near the centromeres, for less than 50 per cent. of the paired arms had terminal chiasmata in these plants compared with 66 per cent. in the control. Similarly the increase in chiasma frequency after irradiation during late diplotene is more marked terminally than interstitially, with over 75 per cent. of the paired arms having terminal chiasmata. However, there is little change in the position of the chiasmata accompanying the rise in chiasma frequency after irradiation of early pachytene. Thus it would appear that the amount of terminalisation is largely independent of the chiasma frequency. There is little difference in the amount of terminalisation in the plants irradiated during non-sensitive periods and that of the control.

Finally, in contrast with the results of Marquardt (I95I) with Vicia, there was no appreciable difference between the responses of the long and the short chromosomes. Further, there were no differences in the amount of variation between cells within anthers after the different treatments ( $c f$. Mather, I934). 


\section{DISCUSSION}

The increase in chiasma frequency observed after irradiation during late diplotene at first sight contradicts the generally accepted view that chiasma formation takes place during pachytene. However, the apparent repositioning of chiasmata that accompanied this change suggests that the response is largely due to the delay or failure of terminalisation rather than a true increase in crossing over. Terminalisation of chiasmata has been shown to occur in Lilium spp. (Darlington, 1937), and it is assumed that a certain proportion of the terminal chiasmata are regularly lost in normal plants of the present material. Failure of terminalisation may well result from chromosome stickiness which holds the bivalents more firmly together. Such stickiness does not persist for very long (Darlington and La Cour, 1944), but in the majority of cases involving treatment of late diplotene, irradiation and fixation were carried out on the same day. This period is comparable to that given by Darlington and La Cour (1944) for the duration of stickiness induced by a similar dose. Thus failure of terminalisation is not to be expected, and indeed is not found, after the irradiation of early diplotene. Similarly it is extremely unlikely that such an explanation can be applied to the increase in chiasma frequency resulting from the irradiation of late zygotene-early pachytene, since on the average six days intervened between treatment and fixation, and further, no change in the position of the chiasmata was observed. Finally, it is also extremely unlikely that the drop in chiasma frequency after premeiotic irradiation is due to an effect on terminalisation since a considerable time elapsed between treatment and fixation.

It appears, therefore, that there are at least two main radiosensitive processes which are important in chiasma formation. The timing of the first of these processes strongly suggests that it is DNA synthesis, for it has been shown (Taylor and McMasters, I954) that this occurs at a bud length of IO-I I mm. in this species. The irradiation was carried out therefore during, or perhaps just before, DNA synthesis. This period has been shown to be very radiosensitive, quite small doses delaying DNA synthesis for a considerable time (Howard and Pelc, I953). Such a delay may result in a lack of synchronisation of cell processes and affect chiasma formation in a number of ways. First, the delay may be responsible for the observed disturbance in chromosome coiling, and in turn this reduction in coiling may be responsible for the drop in chiasma frequency ( $c f$. Darlington, 1940). Alternatively the delay may reduce the time available for effective pairing (Darlington, 1940); there was, however, little evidence of failure of pairing at pachytene in these plants. Nevertheless the relatively greater drop in terminal as opposed to proximal chiasmata could be explained by restricted pairing, which starts at the centromere. Finally, it is possible that the delay in DNA synthesis brings about 
structural aberrations in the chromosomes which later prevent crossing over. It is doubtful, however, whether direct chromosome breakage is involved, for while Mitra (1958) finds that this stage is particularly susceptible to breakage, a peak in sensitivity at this time was not found by Sparrow (195I).

The timing of the second sensitive period at or perhaps slightly before the stage during which chiasma formation is generally considered to occur, suggests that this, or some intimately connected mechanism, is the process affected. Two main classes of action may be considered:

(i) Direct action, by the production of structural defects in the chromosomes, either direct breakage or weaknesses such as "gaps" (Revell, I955) which may be local uncoiling of the chromosomes.

(ii) Indirect action, by affecting processes leading to chiasma formation.

A number of considerations make the first alternative unattractive. First, while there is evidence that chromatid breaks are distributed randomly along the chromosome (Rieger and Michaelis, I959), the distribution of induced cross-overs in Drosophila is by no means at random (Muller, 1925). Such a non-random pattern of induced crossing over suggests that the radiation affects some process controlling recombination in the chromosome or complement as a whole. Preferential exchange between breaks in certain regions of the chromosome at the expense of those in others cannot, however, be entirely discounted. Secondly, the majority of breaks recovered after irradiation at this stage involve only one strand (Mitra, 1958). Therefore a mechanism, such as that suggested by Darlington (1940), to ensure complementary exchange between two of the four strands must be postulated. According to Darlington's (1940) hypothesis, however, chromatid breakage could only lead to a change in the position of the chiasmata, not to an increase in their number, for the amount of crossing over is assumed to depend on the degree of coiling.

On the other hand, it is difficult to specify any definite mechanism controlling recombination in the nucleus as a whole, mainly because of a lack of basic physiological information. Whether the increase in chiasma frequency results from the suppression of other cell processes competing for energy from a common supply or from the removal of some other kind of limitation, cannot be determined. A limitation to the number of chiasmata per nucleus which leads to competition between bivalents has been described by Mather (1936). There is no evidence that it is a cell limit of this nature that has been affected by the radiation, since no correlation between the number of chiasmata in the large and small chromosomes was found. Such evidence is not, however, conclusive, for it depends on the assumption that the cell limit is constant from cell to cell, which may or may not be true. 
Taking the results as a whole, an indication of the time of chiasma formation can be obtained. If chiasma formation is a relatively short process, it would appear that it cannot take place earlier than late zygotene. In so far as there is a relation between chiasma formation and crossing over, whether a one to one relation or a relation of the kind envisaged by Pritchard (1960), the same will be true for recombination. Thus the data are inconsistent with hypotheses such as that of Pritchard (1946) which require recombination to take place earlier than pachytene. Similarly, the results add to the evidence which suggests that crossing over is a breakage phenomenon, or at least partly so (Pontecorvo, I958), for it is known that DNA synthesis (Swift and Kleinfeld, I953; Taylor and McMasters, 1954) and chromosome organisation (Mitra, 1958) takes place no later than leptotene.

Finally, in contrast to the results from other experiments, the data reveal that the irradiation is effective during only relatively short periods of the meiotic and premeiotic cycle ( $c f$. Mather, 1934; Marquardt, 195I). In the absence, however, of reliable information on the stage at which the irradiation was carried out and the extent of any meiotic delay induced by the treatment in these experiments, it is difficult to determine whether the difference between the various species used is real or not. Real differences in the response of different species to radiation must, however, be expected especially between species which on the one hand have restricted pairing and localised chiasmata and those which on the other hand have complete pairing and randomly distributed chiasmata, as in Lilium longiflorum (Darlington and La Cour, 1953). Clearly, different basic mechanisms are operative in these cases.

\section{SUMMARY}

I. The effect on chiasma frequency of the gamma irradiation of different stages in the microsporogenesis of Lilium longiflorum has been investigated.

2. Responses to radiation were found at three different and relatively short stages:

(a) Just prior to the start of meiosis.

(b) Early pachytene.

(c) Late diplotene.

3. The response at the last of these stages is interpreted as arising from a failure of terminalisation, while the responses at the other two stages are taken to be true changes in crossing over.

4. It is suggested that the first response is due to an effect on DNA synthesis, while the second is due to a more direct effect on the mechanism of chiasma formation.

5. The data support the generally accepted view that chiasma formation takes place during pachytene. 
Acknowledgments.-I would like to thank Prof. C. D. Darlington and Dr D. R. Davies, for useful discussion of the results.

\section{REFERENCES}

Darlington, C. D. 1937. Recent Advances in Cytology. Churchill, London.

DARLington, C. D. 1940. The prime variables of meiosis. Biol. Revs., 15, 307-322.

DARlington, C. D., AND LA CoUR, L. F. 1944. Chromosome breakage and the nucleic acid cycle. F. Genet., 46, I80-267.

DARLington, C. D., AND LA COUR, L. F. I953. The classification of radiation effects at meiosis. Suppl. Heredity, 6, 41-55.

ERICKsON, R. O. 1948. Cytological and growth correlations in the flower bud and anther development of Lilium longiflorum. Amer. F. Bot., 35, 729-739.

HOWARD, A., AND PELC, S. R. 1953. Synthesis of desoxyribonucleic acid in normal and irradiated cells and its relation to chromosome breakage. Suppl. Heredity, $6,26 \mathrm{I}-273$.

MARQUARDT, H. I951. Die Wirkung der Rontgenstrahlen auf die Chiasma frequenz in der Meiosis von Vicia faba. Chromosoma, 4, 232-238.

MATHER, K. 1934. The behaviour of meiotic chromosomes after X-irradiation. Hereditas, 19, 303-322.

MATHER, к. 1936. Competition between bivalents during chiasma formation. Proc. Roy. Soc., 120, 208-227.

MITRA, s. 1958. Effects of X-rays on chromosomes of Lilium longiflorum during meiosis. Genetics, 43, 77 I-789.

MULLER, H. J. 1925. The regionally differential effects of X-rays on crossing over in autosomes of Drosophila. Genetics, 10, 470-507.

MURRAY, G. s. 1959. Radiation Dosimetry in Cobalt 6o installation ${ }_{2} \mathrm{C}_{1}$. UKAEA Research Group report.

PONTECORvo, G. 1958. Trends in Genetic Analysis. Columbia U.P., New York.

PRITCHARD, R. H. 196o. Localised negative interference and its bearing on models of gene recombination. Genet. Res., I, I-24.

REES, H. 1955. The genotypic control of chromosome behaviour in rye. I. Inbred lines. Heredity, 9, 93-г 16.

REvell, S. н. 1955. A new hypothesis for chromatid changes. Proc. of Radiobiology Symp. Liege 1954, 243-253.

RIEGER, R., AND MICHAELIS, A. 1959. Vergleichende Untersuchungen zur Verteilung durch Verschiedene Mutagene Induzierter Brüche über den Chromosomensatz von Vicia faba L. Chromosoma, ro, 163-1 78 .

SPARROW, A. H. I95I. Radiation sensitivity of cells during mitotic and meiotic cycles with emphasis on possible cytochemical changes. Ann. N.Y. Acad. Sci., 5r, 1508-1540.

SWIFT, H., AND KLEINFELD, R. 1953. DNA in grasshopper spermatogenesis, oogenesis and cleavage. Physiol. Zool., 26, 301-311.

sYBENGA, J. 1960. The effect of gamma rays on frequency and localisation of chiasmata in Crotalaria Intermedia. Abstract 166, Radiation Research, 12, 478.

TAYLOR, J. H., AND MCMASTERS, R. D. 1954. Autoradiographic and microphotometric studies of desoxyribose nucleic acid during microgametogenesis in Lilium longiflorum. Chromosoma, 6, 489-521. 